\title{
Treatment Options for Atrophic Ridges Based on Anatomical Locations of the Missing Teeth
}

Keywords: Atrophic maxilla; Atrophic mandible; Sinus augmentation; Implant lateral to inferior alveolar nerve.

\begin{abstract}
Differences in anatomy, biomechanical loading and aesthetic demands make treatment needs for implant placement at differen anatomical locations distinct from one another.

In the atrophic posterior maxilla, vertical bone deficiency can be predictably augmented with sinus augmentation procedure. In the edentulous anterior mandible, the improvements in the mechanical properties of titanium alloys and implant designs have enabled the use of dental implants in limited mesial-distal space. Various techniques have also yielded predictable results for horizontal ridge augmentation. However challenges remain in the atrophic anterior maxilla where soft tissue aesthetics is of paramount importance to the success of the restoration; and in the atrophic posterior mandible where the presence of inferior alveolar nerve limits the quantity of bone volume. The aim of this article is to discuss the challenges encountered at different anatomical locations and to present the various surgical treatment options available for each site.
\end{abstract}

\section{Introduction}

The placement of implants at various anatomical locations is met with site-specific challenges. Differences in anatomy, biomechanical loading and aesthetic demands make treatment needs at different locations distinct from one another. Successful esthetic and functional implant rehabilitation relies on sufficient bone volume in the vertical and horizontal dimensions, adequate bone contours, ideal implant positioning and angulation, periodontally healthy periimplant soft tissue, adequate soft tissue contours, and appropriate emergence profile [1]. In the anterior maxilla, the loss of buccal bone upon extraction and its subsequent bone remodelling poses aesthetic concerns [2-3]. In the anterior mandible, the residual bone often has knife-edge morphology. In the posterior maxilla, proximity to the maxillary sinuses coupled with poor bone quality poses challenges, whereas implant therapy in the posterior mandible is complicated by the closeness to the inferior alveolar nerve [4,5]. In addition, complex alveolar defects resulting from previously failed implant sites also present difficulties [6].

Developments in surgical technique and implant material have by and large solved the concerns associated with the atrophic posterior maxilla, anterior mandible, and small alveolar defects. Maxillary sinus augmentation has been shown to be the most predicable bone augmentation procedure for implant placement [7]. Guided bone regeneration (GBR) has also yielded favorable results to treat dehiscence and fenestrations [8]. The improvements in the mechanical properties of titanium alloys and implant designs have enabled the use of dental implants in limited mesial-distal space in the anterior mandible [9]. However, challenges remain in the atrophic anterior maxilla where soft tissue aesthetics is of paramount importance to the success of the restoration; and in the atrophic posterior mandible

\section{Journal of Oral Biology}

\section{Stuti Muchhala*, Motoharu Unozawa, Wendy CW Wang and Cheryl G Robins}

Department of Periodontology and Implant Dentistry, New York University, USA

\section{*Address for Correspondence}

Stuti Muchhala, Department of Periodontology and Implant Dentistry, New York University, Clinic 5W, 345 E 24th St, New York, NY 10010, USA, Tel: +1-347-726-0888; E-mail: Sdm460@nyu.edu

\section{Submission: 15 January, 2018}

Accepted: 16 February, 2018

Published: 26 February, 2018

Copyright: ( 2018 Muchhala S, et al. This is an open access article distributed under the Creative Commons Attribution License, which permits unrestricted use, distribution, and reproduction in any medium, provided the original work is properly cited.

where vertical augmentation is associated with a high prevalence of complications $[10,11]$.

The choice of an appropriate surgical solution for a site-specific problem or a complex defect depends on an understanding of the expected outcome and limitation of the chosen procedure and its associated complication rate. The aim of this review article is to discuss the challenges encountered at different anatomical locations and to present the various surgical treatment options available for each site.

\section{Materials and Methods}

A critical review of the literature was conducted to select pertinent full-length articles published in English. The electronic Medline (PubMed) and Cochrane Library search covered all human and animal clinical trials conducted from 1991 to 2017 in which the above-mentioned bone augmentation procedures were performed. Additionally, a hand search of journals included the following: Clinical Oral Implants Research, Clinical Implant Dentistry and Related Research, Journal of Oral Implantology, International Journal of Oral and Maxillofacial Implants, International Journal of Periodontics and Restorative Dentistry, Journal of Oral and Maxillofacial Surgery, International Journal of Oral and Maxillofacial Surgery, Journal of Periodontology, Journal of Clinical Periodontology. Only publications in English were included in this systematic review. Keywords utilized included "dental implants", "bone grafts", and "sinus grafts (or) sinus augmentation (or) maxillary sinus graft (or) maxillary sinus augmentation" to identify all articles where the sinus bone augmentation (SG) technique was utilized. A similar approach was used to identify other bone grafting techniques, including guided bone regeneration procedures (GBR) either prior to or at the time of implant placement, on lay grafting $(\mathrm{OG})$ others including distraction osteogenesis (DO), ridge splitting or expansion (RS), "atrophic maxilla", "atrophic mandible" and "implant lateral to inferior alveolar nerve".

\section{Search stratergy}

An electronic search into the two databases MEDLINE (via 
Citation: Muchhala S, Unozawa M, Wang MCW, Robins CG. Treatment Options for Atrophic Ridges Based on Anatomical Locations of the Missing Teeth. J Oral Biol. 2018; 5(1): 6

ISSN: 2377-987X

PubMed) and EMBASE (via OVID) was performed to identify systematically the available literature. The search string comprised the combination of keywords (i.e. medial subject's headings MeSH) and free text terms.

\section{Study selection and inclusion criteria}

Studies included in this structured review, fulfilled the following inclusion criteria:

1. Randomized and non-randomized clinical trials, cohort studies, case control studies, and case reports;

2. Relevant data only on bone augmentation;

3. A minimum number of five patients completed;

4. Follow-up data available of a minimum of 12 months of prosthetic loading; and

\section{Published in English.}

To increase the data available for the clinical outcomes (vertical bone gain/ loss and complication rate of the procedure) of GBR, the inclusion criterion (\#4) was modified from a minimum prosthetic loading of 12 months to the time of abutment connection. The studies included both animal and human data. No restrictions were posed in terms of minimum number of patients enrolled or follow-up data.

\section{Exclusion criteria}

1. Augmentations performed on implants placed at the time of tooth extraction (type 1, International Team for Implantology (ITI) classification) were excluded.

2. Studies not fulfilling the above-mentioned inclusion criteria.

3. Studies describing techniques without reporting clinical outcomes.

4. Studies providing only histological data.

5. Studies describing bone augmentation procedures as a treatment modality following peri-implantitis, trauma, or tumor ablation, or therapy for various medical syndromes.

\section{Results}

The results of this review are based on clinical findings and literature review. There are assimilated in Table 1 summarizing the challenges encountered at different anatomical locations and the surgical options for site-specific implant placement.

\section{Discussion}

\section{Treatment planning}

Detailed patient assessment, diagnostic wax up of the anticipated restoration in relation to the edentulous ridge, and $\mathrm{CBCT}$ with radiographic templates improves the assessment of edentulous site and are essential for treatment planning [12,13]. Recently, 3-D printing has become commercially available and the CBCT DICOM can be converted to a stereolithographic file which can then be used to construct a three dimensional true size cranial model [14]. Clinicians can familiarize themselves with a patient's edentulous ridges and rehearse the planned procedure (Figure 1). Minimally invasive implant surgery is gaining popularity. The essence of minimally invasive procedures should not be one that sacrifices visibility for the perceived simplicity of surgery; but a procedure that encompasses an efficient and meticulous surgery with minimum intra-operative complication based on thorough pre-operative assessment and planning, which in turn leads to faster healing.

However, clinicians often do not have direct visualization of the defect topography or the anatomical landmark; resulting in risks of implant mal position, undetected fenestration, dehiscence, damages to vital structures or perforation of the Schneiderian membrane [15]. Accurate pre-operative assessment allows the planned procedure to be minimally invasive through avoidance of unexpected clinical findings, and reduction in surgical time, thereby improves patient comfort, and minimizes post-operative morbidity and complication.

\section{Anterior maxilla}

Achieving an aesthetic restoration with harmonious hard and

Table 1: Summary of the procedure options, indications and limitations for site-specific implant placement.

\begin{tabular}{|c|c|c|c|}
\hline Area & Procedures & Indication & Limitations \\
\hline \multirow[t]{2}{*}{$\begin{array}{c}\text { AMAN } \\
\text { (Ant Mandible) }\end{array}$} & \multirow{2}{*}{$\begin{array}{c}\text { GBR } \\
\text { Ridge Splitting } \\
\text { Block bone graft }\end{array}$} & \multirow{2}{*}{$\begin{array}{l}\text { Small defect } \\
\text { Adequate height } \\
\text { Large defect }\end{array}$} & $\begin{array}{c}\text { Possible dehiscence } \\
\text { Need two segment in long span }\end{array}$ \\
\hline & & & Possible exposure and infection \\
\hline $\begin{array}{c}\text { AMAX } \\
\text { (Ant Maxillae) }\end{array}$ & $\begin{array}{l}\text { Tunnel technique } \\
\text { GBR } \\
\text { Ridge Splitting } \\
\text { Block bone graft }\end{array}$ & $\begin{array}{l}\text { Aesthetic area } \\
\text { Small defect } \\
\text { With height } \\
\text { Large defect }\end{array}$ & $\begin{array}{c}\text { Technique sensitive } \\
\text { May need additional graft } \\
\text { May need additional graft } \\
\text { Possible exposure and infection }\end{array}$ \\
\hline $\begin{array}{l}\text { POMAN } \\
\text { (Posterior } \\
\text { mandible) }\end{array}$ & $\begin{array}{c}\text { GBR } \\
\text { Ridge Splitting } \\
\text { Block bone graft } \\
\text { Implant lateral to IAN }\end{array}$ & $\begin{array}{c}\text { GBR } \\
\text { With height } \\
\text { Large defect } \\
\text { Vertical defect, need with }\end{array}$ & $\begin{array}{c}\text { GBR } \\
\text { Possible dehiscence and infection } \\
\text { better with interdental defect } \\
\text { Implant lateral to IAN }\end{array}$ \\
\hline $\begin{array}{c}\text { POMAX } \\
\text { (Post Maxillae) }\end{array}$ & $\begin{array}{c}\text { Sinus augmentation } \\
\text { Osteotome } \\
\text { GBR } \\
\text { Ridge Splitting } \\
\text { Block bone graft }\end{array}$ & $\begin{array}{l}\text { Most predictable pro } \\
\text { Minimally invasive } \\
\text { Atrophic region } \\
\text { Very thin ridge } \\
\text { Large defect }\end{array}$ & $\begin{array}{c}\text { Bleeding, thick lateral wall, Perforation } \\
\text { Case selection } \\
\text { Need staged } \\
\text { May need sinus augmentation }\end{array}$ \\
\hline
\end{tabular}




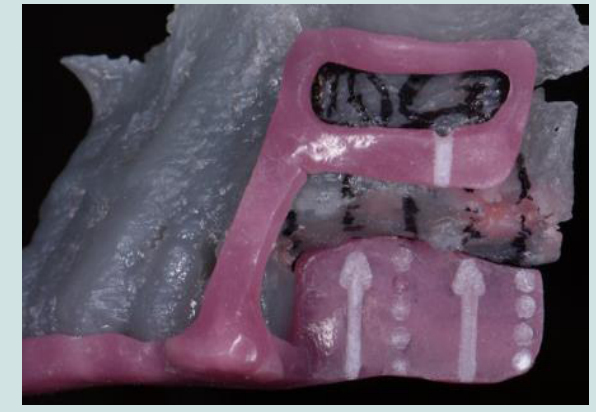

Figure 1: Surgical guide made on a 3-D printed model which replicates the patient's anatomy for precise lateral window location for sinus augmentation procedure.

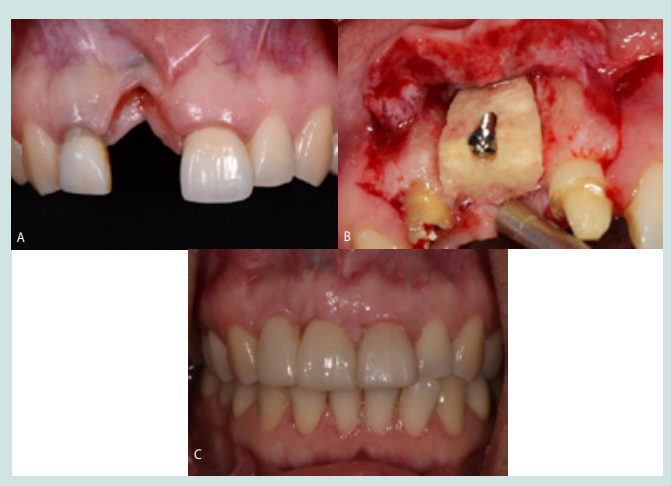

Figure 2: A: Patient presents with a challenging defect in the anterior maxilla. B: Allogenic block bone grafted in the defect graft was. C: Two years follow up shows successful results with restoration despite slight blunting of interdental papilla.

soft tissue topography in the anterior maxilla is not an easy task (Figure 2A-2C) [16]. A variety of different procedures for hard tissue augmentation have been described, like guided bone regeneration, onlay block bone graft, ridge split or ridge expansion technique and distraction osteogenesis [17]. However dehiscence, shortening or loss of the inter dental papillae remains a frequent post-surgical finding. Buser D and colleagues have illustrated maintenance of bone level and stable mid-buccal soft tissues using simultaneous implant placement with guided bone regeneration (GBR) in a 6-year follow up study [18]. However, the inter dental papillae often appeared blunted following the GBR procedure. Cosyn J and colleagues showed that immediate implant treatment have better aesthetic outcomes than simultaneous implant placement with GBR, and staged implant treatment in grafted bone. Incomplete papilla fill were often associated with the latter two groups. The authors attributed this finding to the number of surgical interventions and repeated papilla elevation [19].

The vascularity of the papilla is supplied by the vascular anastomoses crossing the alveolar ridge [20]. The recurring disruption to the vascular supply through flap elevation can lead to scar tissue formation as a result of fibroblasts becoming prematurely activated and forming excess fibrotic scar tissue. A favorable soft tissue architecture and volume prior to large augmentation procedures is also important so that primary wound closure can be achieved. The soft tissue graft creates an advantageous blood supply bed for the bone augmentation procedure resulting in higher predictability and setting a solid foundation for future implant success and an esthetically pleasing outcome [21].

\section{Posterior maxilla}

Implant restorations in the posterior maxilla need to sustain functional loading. Improvements in implant surface technology have drastically improved the survival rate of dental implants in the posterior maxilla, which has inherently poorer bone quality [22]. The challenges associated with insufficient vertical bone volume are addressed with maxillary sinus augmentation, and non-inductive materials with slow resorption have been shown to be more superior in forming and maintaining bone than inductive materials [23,24].

Sinus augmentation can be performed directly through a lateral window or indirectly with a transcrestal approach [25]. The lateral window approach allows direct access and visualization of the sinus cavity for Schneiderian membrane elevation. While the direct technique has evolved into a predictable surgical modality, concerns over its technique-sensitivity and potential intra and post-operative complications have led to the introduction of the transcrestal osteotome technique for sinus augmentation [26]. It was presented as a less invasive and less time-consuming technique with a lower rate of post-operative complications [27]. However, the osteotome technique is a blind technique. The lack of visibility coupled with limited access during manipulation of the membrane can lead to perforation of the sinus membrane when using the twist drill or osteotomes. Moreover, the bone graft substitutes are blindly packed beneath the membrane, which increases the risk of membrane perforation. Despite the claim of minimum invasiveness, a systemic reviewed showed membrane perforation remains the most frequently reported complication, observed in $0 \%$ to $27 \%$ of indirect sinus floor elevation procedures [28]. The limited control over the operating site also reduces the volume of bone augmentation compared to that obtained with the lateral window technique. Furthermore, the trauma induced by percussion with the surgical hammer, along with hyperextension of the neck during the osteotome technique can lead to displacement of otoliths in the ears resulting in the appearance of benign paroxysmal positional vertigo and discomfort which can be a concern especially in the older population [29]. A case of early implant failure is shown in (Figures 3A-3C), where microfractures of

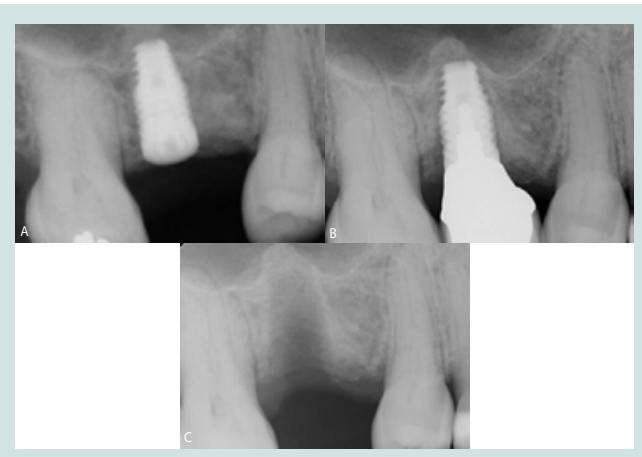

Figure 3: A: Periapical radiograph of an implant at the maxillary right first molar site with osteotome technique used for sinus augmentation. B: Periapical radiograph of the implant restoration showing radiolucency along the body of the implant following loading. C: Periapical radiograph at maxillary right first molar site following implant removal. 
Citation: Muchhala S, Unozawa M, Wang MCW, Robins CG. Treatment Options for Atrophic Ridges Based on Anatomical Locations of the Missing Teeth. J Oral Biol. 2018; 5(1): 6

the peri implant interfaces was likely the cause [30].

The osteotome technique may however improve initial implant primary stability on the premise that, condensing the cancellous bone of the maxillary alveolar process can increase the bone density.

Sinus augmentation has been demonstrated to be a reliable treatment modality for gaining vertical bone volume for implant placement in the posterior maxilla. The predictability of the sinus augmentation and implant placement procedure relies more on host factors, such as the health status of the sinus, size and location of the endosseous anastomosis, lateral wall and Schneiderian membrane thickness, and residual bone height, than the biomaterials used or techniques chosen [31,32]. Thorough pre-surgical assessment remains the key for success.

\section{Anterior mandible}

The absence of vital structures coupled with the frequently encountered type II/III bone quality makes the anterior region of the mandible suitable for implant placement [3]. Nevertheless, the thinning of the coronal region of the alveolar ridge is a common finding. Reduction of the ridge height until adequate bone width is obtained for subsequent apical implant placement may be a nongrafting option, but it is associated with increased crown length, which can compromise aesthetics and access for hygiene. Alternatively, GBR or ridge splitting has been shown to be predictable methods for increasing horizontal bone volume in the anterior mandible $[7,8]$.

Insufficient mesial-distal distance is another concern for single mandibular incisor replacement. This problem can be addressed by the subcrestal placement of a platform switching implant, which has been shown to maintain bone level with $1 \mathrm{~mm}$ clearance from adjacent teeth, narrow diameter implants can also be used in such situations (Figures 4A and 4B) [33-35]. In addition, patients often present with more than one missing lower incisor. However, the reduced functional load and improved mechanical properties of the titanium alloy implants enable the use of long span bridges or cantilever restorations in the anterior mandible region [36].

\section{Posterior mandible}

The atrophic posterior mandible is often associated with high components of cortical bone, reduced vascular supply, superficial muscle attachment and lack of keratinized gingiva, moreover posterior mandible is subject to increased masticatory forces [5]. All these factors can complicate ridge augmentation procedures.

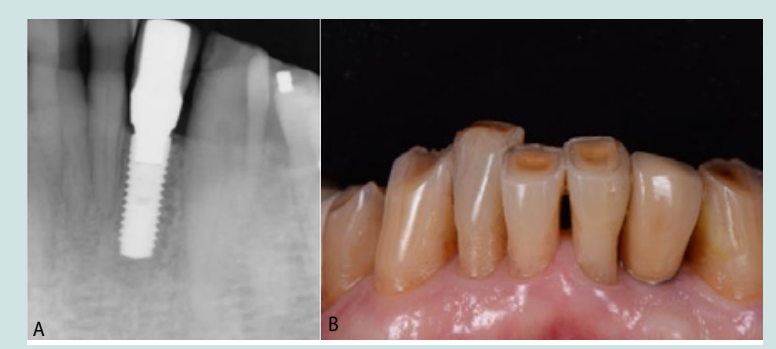

Figure 4: A: Periapical radiograph showing a platform switching implant (Straumann BL 3.3mm) used to replace mandibular lower left lateral incisor. B: Clinical view of the implant support restoration for mandibular lower left lateral incisor.

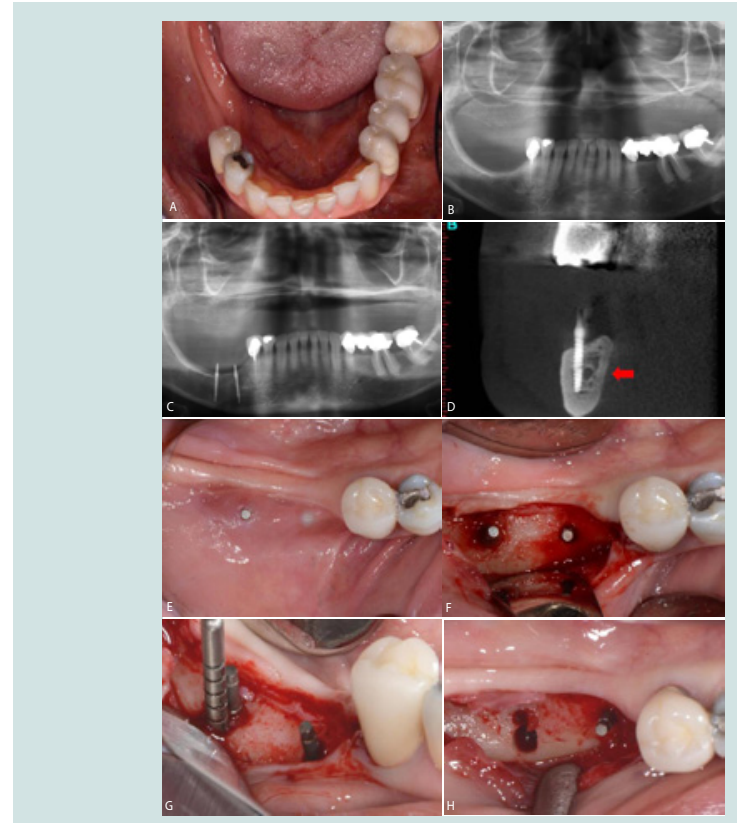

Figure 5A-H: A: Occlusal view of a resorbed mandibular right posterior ridge. B: Pre-operative panoramic radiograph. C: Panoramic radiograph showing two interim implants $(2.2 \mathrm{~mm}$, SmartSlim, EBI, South Korea) placed lateral to inferior alveolar canal. D: CT-Scan image of the interim implant placed lateral to inferior alveolar canal. E: Occlusal view of the interim implants following two months of healing. F: Full thickness flap raised for definitive implants placement. G: Osteotomy of the definitive implants was prepared lateral to the interim implants. $\mathbf{H}$ : The interim implant was removed following completion of osteotomy preparation of the definitive implant.

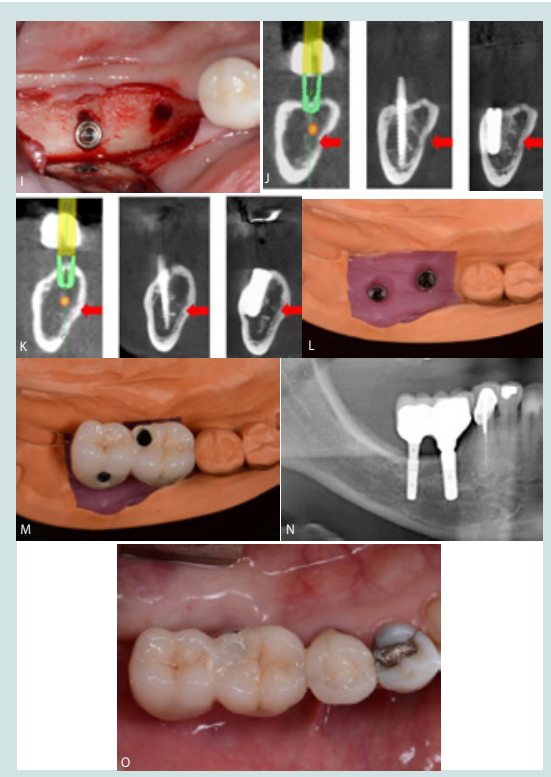

Figure 5I-O: I: A definitive implant was placed in the mandibular right second molar site (3.3 $12 \mathrm{~mm}$ SLA NC, Straumann, Switzerland). J: Sequential CTScan images of the mandibular right second molar site: Simplant@ simulation, interim implant placement, definitive implant placement. K: Sequential CTScan images of the mandibular right first molar site: Simplant@ simulation, interim implant placement, definitive implant placement $(4.1 \times 12 \mathrm{~mm}$ SLA RC Straumann, Switzerland). L: Implant position shown on the fixture cast. M: A screw-retained, splinted restoration was made. N: Panoramic radiograph of the restoration. O: Occlusal view of the restoration in place with screw holes filled with composite resin. 
Citation: Muchhala S, Unozawa M, Wang MCW, Robins CG. Treatment Options for Atrophic Ridges Based on Anatomical Locations of the Missing Teeth. J Oral Biol. 2018; 5(1): 6

\section{ISSN: $2377-987 X$}

Distraction osseogenesis, autogenous onlay graft, and guided bone regeneration have been used to augment these defects with limited degrees of success and predictability, with vertical ridge augmentation remaining the most challenging and least predictable procedure [37-40]. An alternative to grafting bone coronally is to place the implants lateral to the inferior alveolar canal to engage the native residual bone (Figures 5A-5O) [41-44]. This maximizes the chances for successful osseointegration. This is possible because the inferior alveolar canal is closer to the lingual cortical bone, which usually leaves more available bone buccal to the canal for implant placement. However, the risk of violation of the neurovascular bundle remains a concern with implants placed lateral to the canal and careful execution of the planned implant position is needed.

The risks, biological complications, cost and prolonged treatment time associated with bone augmentation procedures have led to the increased popularity of short implants. However, implants with length $\leq 8 \mathrm{~mm}$ should be used with caution in the posterior jaw because their survival rates are reduced significantly when compared to standard implants $>8 \mathrm{~mm}[45,46]$. It is postulated that these unfavorable results occur from overload as shorter implants have less surface area in contact with the osseointegrated bone to dissipate the occlusal forces. More long term studies are needed to ascertain the validity of short implants in the posterior mandible.

\section{Conclusion}

Differences in anatomy, biomechanical loading and aesthetic demands make treatment needs for implant placement at different anatomical locations distinct from one another.

Accurate pre-operative assessment, selection of the most suitable treatment option based on the available evidence, and meticulous execution of the planned surgery are the key parameters for successful outcome.

\section{Mesh Terms}

Sinus Floor Augmentation; Alveolar Ridge Augmentation; Guided Bone Regeneration; Distraction Osteogenesis; Soft Tissue Grafting; Vertical Augmentation; Ridge Augmentation

\section{References}

1. Yang LM, Wessel J (2017) The deficient alveolar ridge: classification and augmentation considerations for implant placement. Clin Update 39: 1-2.

2. Van der Weijden F, Dell'Acqua F, Slot DE (2009) Alveolar bone dimensional changes of post-extraction sockets in humans: a systematic review. J Clin Periodontol 36: 1048-1058.

3. Atwood DA (2001) Some clinical factors related to rate of resorption of residual ridges. 1962. J Prosthet Dent 86: 119-125

4. Wallace SS, Froum SJ (2003) Effect of maxillary sinus augmentation on the survival of endosseous dental implants. A systematic review. Ann Periodontol 8: 328-343.

5. Gallucci GO, Khoynezhad S, Yansane Al, Taylor J, Buser D et al. (2017) Influence of the posterior mandible ridge morphology on virtual implant planning. Int J Oral Maxillofac Implants 32: 801-806.

6. Machtei EE, Mahler D, Oettinger-Barak O, Zuabi O, Horwitz J (2008) Denta implants placed in previously failed sites: survival rate and factors affecting the outcome. Clin Oral Implants Res 19: 259-264.

7. Aghaloo TL, Moy PK (2007) Which hard tissue augmentation techniques are the most successful in furnishing bony support for implant placement? Int J Oral Maxillofac Implants 22 Suppl: 49-70.

8. Milinkovic I, Cordaro L (2014) Are there specific indications for the different alveolar bone augmentation procedures for implant placement? A systematic review. Int J Oral Maxillofac Surg 43: 606-625.

9. Davarpanah M, Martinez H, Tecucianu JF, Celletti R, Lazzara R (2000) Small diameter implants: indications and contraindications. J Esthet Dent 12: 186194.

10. Urban IA, Monje A, Wang HL (2015) Vertical ridge augmentation and soft tissue reconstruction of the anterior atrophic maxillae: a case series. Int $J$ Periodontics Restorative Dent 35: 613-623.

11. Elnayef B, Monje A, Gargallo-Albiol J, Galindo-Moreno P, Wang HL et al. (2017) Vertical ridge augmentation in the atrophic mandible: a systematic review and meta-analysis. Int J Oral Maxillofac Implants 32: 291-312.

12. Benavides E, Rios HF, Ganz SD, An CH, Resnik R et al. (2012) Use of cone beam computed tomography in implant dentistry: the International Congress of Oral Implantologists consensus report. Implant Dent 21: 78-86.

13. Tyndall DA, Price JB, Tetradis S, Ganz SD, Hildebolt C et al. (2012) Position statement of the American Academy of Oral and Maxillofacial Radiology on selection criteria for the use of radiology in dental implantology with emphasis on cone beam computed tomography. Oral Surg Oral Med Oral Pathol Oral Radiol 113: 817-826.

14. Froum SJ, Cho SC, Loomer PM, Georgantza A, Suzuki T (2016) Dental Learning

15. Sclar AG (2007) Guidelines for flapless surgery. J Oral Maxillofac Surg 65 (7 Suppl 1): 20-32.

16. Grunder U, Spielman HP, Gaberthüel T (1996) Implant-supported single tooth replacement in the aesthetic region: a complex challenge. Pract Periodontics Aesthet Dent 8: 835-842.

17. Chiapasco M, Zaniboni M, Boisco M (2006) Augmentation procedures for the rehabilitation of deficient edentulous ridges with oral implants. Clin Oral Implants Res 17 Suppl 2: 136-159.

18. Buser D, Chappuis V, Kuchler U, Bornstein MM, Wittneben JG et al. (2013) Long-term stability of early implant placement with contour augmentation. J Dent Res 92 (12 suppl): 176S-182S

19. Cosyn J, Eghbali A, Hanselaer L, De Rouck T, Wyn I et al. (2013) Four modalities of single implant treatment in the anterior maxilla: a clinical, radiographic, and aesthetic evaluation. Clin Implant Dent Relat Res 15: $517-$ 530.

20. Kleinheinz J, Büchter A, Kruse Lösler B, Weingart D, Joos U (2005) Incision design in implant dentistry based on vascularization of the mucosa. Clin Oral Implants Res 16: 518-523.

21. Le B, Nielsen B (2015) Esthetic implant site development. Oral Maxillofac Surg Clin North Am 27: 283-311.

22. Jaffin RA, Berman CL (1991) The excessive loss of Branemark fixtures in type IV bone: a 5-year analysis. J Periodontol 62: 2-4

23. Mohan N, Wolf J, Dym H (2015) Maxillary sinus augmentation. Dent Clin North Am 59: 375-388.

24. Froum SJ, Tarnow DP, Wallace SS, Rohrer MD, Cho SC (1998) Sinus floor elevation using anorganic bovine bone matrix (OsteoGraf/N) with and without autogenous bone: a clinical, histologic, radiographic, and histomorphometric analysis--Part 2 of an ongoing prospective study. Int $\mathrm{J}$ Periodontics Restorative Dent 18: 528-543.

25. Tatum H Jr (1986) Maxillary and sinus implant reconstructions. Dent Clin North Am 30: 207-229.

26. Summers RB (1994) A new concept in maxillary implant surgery: the osteotome technique. Compendium 15: 154-156.

27. Zitzmann NU, Schärer P (1998) Sinus elevation procedures in the resorbed posterior maxilla: comparison of the crestal and lateral approaches. Oral Surg Oral Med Oral Pathol Oral Radiol Endod 85: 8-17. 
Citation: Muchhala S, Unozawa M, Wang MCW, Robins CG. Treatment Options for Atrophic Ridges Based on Anatomical Locations of the Missing Teeth. J Oral Biol. 2018; 5(1): 6 .

28. Esposito M, Grusovin MG, Rees J, Karasoulos D, Felice P, et al. (2010) Effectiveness of sinus lift procedures for dental implant rehabilitation: a cochrane systematic review. Eur J Oral Implantol 3: 7-26.

29. Peñarrocha-Diago M, Rambla-Ferrer J, Perez V, Pérez-Garrigues H (2008) Benign paroxysmal vertigo secondary to placement of maxillary implants using the alveolar expansion technique with osteotomes: a study of 4 cases. Int J Oral Maxillofac Implants 23: 129-132.

30. Büchter A, Kleinheinz J, Wiesmann HP, Kersken J, Nienkemper M, et al. (2005) Biological and biomechanical evaluation of bone remodelling and implant stability after using an osteotome technique. Clin Oral Implants Res 16: 1-8.

31. Monje A, Diaz KT, Aranda L, Insua A, Garcia-Nogales A, et.al. (2016) Schneiderian membrane thickness and clinical implications for sinus augmentation: a systematic review and meta-regression analyses. J Periodontol 87: 888-899.

32. Shanbhag S, Karnik P, Shirke P, Shanbhag V (2014) Cone-beam computed tomographic analysis of sinus membrane thickness, ostium patency, and residual ridge heights in the posterior maxilla: implications for sinus floor elevation. Clin Oral Implants Res 25: 755-760.

33. Tarnow DP, Cho SC, Wallace SS (2000) The effect of inter-implant distance on the height of inter-implant bone crest. J Periodontol 71: 546-549.

34. Vela X, Méndez V, Rodríguez X, Segalá M, Tarnow DP (2012) Crestal bone changes on platform-switched implants and adjacent teeth when the toothimplant distance is less than $1.5 \mathrm{~mm}$. Int J Periodontics Restorative Dent 32 : 149-155.

35. Cordaro L, Torsello F, Mirisola Di Torresanto V, Rossini C (2006) Retrospective evaluation of mandibular incisor replacement with narrow neck implants. Clin Oral Implants Res 17: 730-735.

36. Chiapasco M, Casentini P, Zaniboni M, Corsi E, Anello T (2012) Titaniumzirconium alloy narrow-diameter implants Straumann Roxolid $\left({ }^{\circledR}\right)$ ) for the rehabilitation of horizontally deficient edentulous ridges: prospective study on 18 consecutive patients. Clin Oral Implants Res 23: 1136-1141.
37. Rocchietta I, Fontana F, Simion M (2008) Clinical outcomes of vertical bone augmentation to enable dental implant placement: a systematic review. J Clin Periodontol 35 (8 Suppl): 203-215

38. Urban IA, Jovanovic SA, Lozada JL (2009) Vertical ridge augmentation using guided bone regeneration (GBR) in three clinical scenarios prior to implant placement: a retrospective study of 35 patients 12 to 72 months after loading. Int J Oral Maxillofac Implants 24: 502-510.

39. Esposito M, Grusovin MG, Felice P, Karatzopoulos G, Worthington HV, et al (2009) The efficacy of horizontal and vertical bone augmentation procedures for dental implants: a cochrane systematic review. In: Chiappelli $F$ (ed.) Evidence-Based Practice: Toward Optimizing Clinical Outcomes, Springer, Heidelberg, Europe, pp. 195-218.

40. Chiapasco M, Romeo E, Casentini P, Rimondini L (2004) Alveolar distraction osteogenesis vs. vertical guided bone regeneration for the correction of vertically deficient edentulous ridges: a 1-3 year prospective study on humans. Clin Oral Implants Res 15: 82-95.

41. Krekmanov L, Kahn M, Rangert B, Lindström H (2000) Tilting of posterior mandibular and maxillary implants for improved prosthesis support. Int J Oral Maxillofac Implants 15: 405-414.

42. Daróz SR, Cardoso ES, Manso MC, Vidigal GM Jr (2013) Evaluation of bone width lateral to the mandibular canal as an alternative approach for implant installation. Implant Dent 22: 97-101.

43. Peñarrocha Diago M, Maestre Ferrín L, Peñarrocha Oltra D, Canullo L, Calvo Guirado JL (2013) Tilted implants for the restoration of posterior mandibles with horizontal atrophy: an alternative treatment. J Oral Maxillofac Surg 71: 856-864.

44. Pancko F, Dyer J, Weisglass S, Kraut RA (2010) Use of tilted implants in treatment of the atrophic posterior mandible: a preliminary report of a novel approach. J Oral Maxillofac Surg 68: 407-413.

45. Lemos CA, Ferro-Alves ML, Okamoto R, Mendonça MR, Pellizzer EP (2016) Short dental implants versus standard dental implants placed in the posterior jaws: a systematic review and meta-analysis. J Dent 47: 8-17.

46. Thoma DS, Cha JK, Jung UW (2017) Treatment concepts for the posterior maxilla and mandible: short implants versus long implants in augmented bone. J Periodontal Implant Sci 47: 2-12.
Acknowledgements

Special thanks to Dr. Dae Seop Lee, BDS, PhD for his contribution of clinical cases and revision of the manuscript. 